\title{
A Method for Isolated Worker/ Worker from Home to produce Diary-Based Performance Evidence: A Qualitative Study.
}

Ching-I Chen ( $\sim$ d09903013@chu.edu.tw)

Chung Hua University https://orcid.org/0000-0002-4376-5092

\section{Research Article}

Keywords: Job breakdown structure (JBS), Activity dictionary (AD), Participatory performance appraisal system (PPAS), Work from Home (WFH), Diary-based performance evidence (DBPE)

Posted Date: April 9th, 2021

DOl: https://doi.org/10.21203/rs.3.rs-384439/v1

License: (c) (i) This work is licensed under a Creative Commons Attribution 4.0 International License.

Read Full License 


\section{Abstract}

\section{Background:}

With the rise of internet usage and the global spread of COVID-19 pandemic in 2020, work from home or isolated working style has become a norm and inevitable to both employers and employees. At the same time, existing/traditional performance appraisal methods are inadequate to respond to this working model and require improvements for better competency.

\section{Objective:}

Using holistic events documentary and subsequent statistical report, the performance evidence of appraisees can be produced in a standardized way, so that the raters can conduct the appraisal based on the official release data and relevant statements presented by the ratee.

\section{Method:}

Based on the field survey of members in modern enterprises/ organizations, an activity classification (i.e., Job Breakdown Structure; JBS) is maneuvered under the guidance of the grounded theory. It combines the prior agreement between both parties (employer and employee) by using an activity dictionary, and an on-duty shorthand method is ready for any worker to document their daily efforts. The mentioned recording efforts are to produce a standard diary log and weekly man-hours statistics/reports. Then, statistical data during the social exchange period is generated, and it can be summarized as his/ her Diary-Based Performance Evidence (DBPE), to facilitate the employee to present oneself in any performance appraisal system.

\section{Results:}

The performance evidence-producing method described in this paper is shown to be competent in appraising the isolated workers/ worker from home to defend their efforts with official release statistical data and his/her supplement statements.

\section{Conclusions:}

With the proposed JBS method, an activity dictionary is used to make a prior agreement between employer and employee. A shorthand method is implemented to facilitate workers, both isolated and work from home, to document their work logs on duty. It is shown to be useful in assisting both the isolated workers and the raters in the performance appraisal process. The proposed method is practical, can easily produce standardize DBPE, and applicable to workers both isolated and work from home, as well as workers of other working styles.

Keywords: Job breakdown structure (JBS); Activity dictionary (AD); Participatory performance appraisal system (PPAS); Work from Home (WFH); Diary-based performance evidence (DBPE). 


\subsection{Introduction}

Performance appraisal has been one of the important tools for enterprises to enhance productivity. The rewards and penalties of the appraisal result are not cause a push and pull effect to the appraisee, but it also generates a rendering effect, to a certain extent, the members within the enterprise. However, it is for long that employees or the public have cast a negative impression of the current/traditional performance appraisal system due to the distrust of the raters. Such distrust may result in declined productivity and, eventually, the loss of profit of the organization. Pursuing a humanistic treatment and the justice in the appraisal system has become a trend of modern enterprises and organizations.

Meanwhile, the increase in the internet usage has created new working styles that did not exist before. Isolated and outlier innovation and targeted group effort of team division are both seen in the practice of such new working styles. In addition, with the global pandemic of Covid-19 since early 2020, the abovementioned work styles have become the norm of various industries. Therefore, under these new working styles, the employees' consistent expectation of justice in appraisal process, and at the same time, a need to resolve the public's stereotypes images of the current system, are the challenges faced by the Human Resources Department (HRD) today.

To tackle the above-mentioned problem, this paper aims at proposing a useful and practical method to produce effective performance evidence that is acceptable for both raters and ratees before the appraisal process. To this end, this paper cites the Participatory Performance Appraisal System (PPAS) formed in the 1980s as a starting point to find the best treatment method for the performance appraisal of any onduty worker. The reason to cite PPAS is based on the reason that it is the only known performance appraisal system that can comply with both the requirements of equity theory and organizational justice. Expecting that the vulnerable party of social exchange (i.e., the employees) will be treated in a humane and consistent manner, it also abides by the concept of procedural justice and the best evidence review. In addition, a feedback is given, from the appraisee to the overall view of the reception process after the appraisal. For which, it forms a corrective mechanism to lower the adverse effect caused by the system.

As mentioned above, in such an appraisal under PPAS, the use of self-reported evidence from the vulnerable party is mandated. Hence, it shall be the only reasonable appraisal method for both $Z$ generation's workers and worker from home. Furthermore, this paper also provides a breakthrough of current PPAS in resolving the issue of "what is the practice of diary-based performance appraisal reports" as mentioned by Greenberg (1987); this might take a step further from their ideal and closer to reality.

The primary objective of this paper is to provide a feasible solution for the best evidence of an employee presented to the performance appraisal process by using his/her own diary log and its related statistical data. Based on the Job Breakdown Structure (JBS), induced both by the knowledge of works' daily activity of the modern enterprise from field observation and the coding maneuver under the grounded theory, a combined Activity Dictionary (AD), which represents the prior agreement between employer and employee, and a series of coding Activity Items (Als) makes it an on-duty shorthand method ready for any worker to document their daily efforts. With these documentation efforts, one can produce a standardized 
diary log. The "standardized" diary of the log is to facilitate their employers to realize the contents within the log, especially if the worker is almost out of their sight. Then, the employee, supplemented by statistical data and diary, edits personal "Diary-Based Performance Evidence (DBPE)". With this manuscript (i.e., DBPE), anyone can participate in any performance appraisal system confidently.

The paper is organized to include the literature review, methodology (includes the implementation steps), case study, interpretations, and findings, as well as discussion and conclusion. Finally, the limitations of this method are addressed and elaborated in detail.

\subsection{Literature Review}

The spread of the global pandemic of covid-19 since 2020 has not decreased, and the chance of worker from home has greatly increased. Accordingly (Dingel \& Neiman, 2020), 37\% of jobs in the United States can be performed entirely from home, and there is significant variation across occupations. For example, managers, educators, and those working in computers, finance, and law are largely able to work from home. Even more, available estimates of the potential number of home-based works (Bick et al., 2020) suggest that a large majority $(71.7 \%)$ of US workers could work from home.

WFH is not only a fairly restricted phenomenon but also one that lacks impetus; it is mainly an informal working arrangement (Aguilera et al., 2016). Both employees and employers are of the opinion that WFH has uncertain advantages coupled with immediate disadvantages. Since the pandemic, Delventhal et al. (2021) pointed out many advantages of WFH. Quote from their study: "There are three important effects: 1) Jobs move to the core of the city, while residents move to the periphery, 2) Traffic congestion eases and travel times drop, 3) Average real estate prices fall, particularly declining in core locations and increases in the periphery. Also, workers who are able to switch to telecommuting enjoy large welfare gains by saving commute time and moving to more affordable neighborhoods." And this paper should point out that, Since Covid-19 still exists, there is no need for further study or analysis, anyone can immediately acknowledge that reducing the chance of infection, at the same time, eliminating the potential spread of the virus at the workplace, are both the biggest benefits of WFH.

But WFH also has its fatal shortcomings. Dockery \& Bawa (2020) have pointed out work-level issues, such as: a blurring of work/life separation, less work discipline, inconvenience in communicating with peers, etc. In the same way, employers have concerns about the output progress and possible efficiency doubts, and the suspicion born out of work will have an impact on productivity. Therefore, regardless of the benefits of WFH, or the inevitable trend in the context, the owners and employees of the business must seek to improve their shortcomings. From an organizational point of view, the three most important issues are to maintain overall morale and productivity, reinforce work disciplines, and clearly define rewards and penalties. Therefore, the current performance appraisal should be changed in these work patterns and adjusted accordingly.

For the above-mentioned, new work style, Islami et al. (2018) believe that the use of Management By Objectives (MBO) is the best model for performance appraisal. In fact, this type of performance appraisal 
model takes the delivery objective or promotes productivity as the only consideration for performance evaluation, and was started quietly as early as 1965 .

Although performance appraisal is one of the most important management tools and has been practiced for thousands of years, so far, it is still trying to find answers in more aspects (Bernardin \& Beatty, 1984; Henderson, 1984; Kandula, 2006; Viswesvaran \& Ones, 2000). And, nowadays, it has not been able to get rid of many of its controversies (Bukh \& Mouritsen, 2014; Murphy \& Cleveland, 1995). Among these developments, PPAS is the only one that appeals to the humanistic treatment and impartial requirements of the appraisal system as well as the satisfactory perceived feedback after the appraisal (Roberts, 2003). Its system is based on the equity theory of social exchange (Adams, 1965) with the original intention of fair treatment to employees.

Based on his in-depth observations of contemporary enterprises, Adams (1965) proposed that the issue of equal treatment should be in any social exchange, later known as the 'equity theory'. Because of this, the concept of performance appraisal has revolutionized change. Coupled with several waves of organizational justice initiatives in the 1980s, a new performance appraisal model that only talks about the status of exchange objectives has finally taken shape. Later generations called it PPAS (Cawley, 1998). The process in PPAS was praised by Roberts (2003) as: it can mitigate many of the dysfunctions of traditional performance appraisal systems as well as engender a more 'humane' and ethical human resource management decision-making process.

Roberts (2003) also states, there are several basic elements to form PPAS: 1) Employee participation in the performance appraisal system and planning of its reception procedures, 2) Review only by the best evidence (based on what employees acknowledge), 3) Pre-transaction target determination, and 4) A holistic feedback of the ratee's opinions (satisfaction and fairness perception) after the review. Greenberg (1987) proved through experiments that the greatest perception of the ratee after this reception is that the judgment is not in line with expectations, nor does it detract from satisfaction and fairness perception.

Regarding the best evidence required by PPAS, Greenberg (1987) suggested that employees should be reviewed in a procedural justice-guided process, and the performance evidence provided during the review should be their "voice". Through his experiment, the "voice" means the diary, and the original text quoted as follows: "To the extent that well-accepted performance evaluations enhance worker motivation and performance, a potentially important benefit of using diaries in the performance appraisal process is identified in the present study" (Greenberg, 1987).

Furthermore, Roberts (2003) believe that the implementation of PPAS (the tendency to take care of disadvantaged party, i.e., the employees) and at the same time make it fair to the other party, the following efforts are needed to promote this system:

(1) The degree of neutrality and reliability of performance evidence;

(2) Maintain a consistent dialogue platform, regardless of a normal day or during the review period; 
(3) The appraisee has an aggressive attitude of self-appraisal.

\subsection{Methodology}

As stated in the literature review, "DBPE" provides a quantified performance evidence for any worker. To address this unsolved issue, this paper proposes a method for employees to produce standardized diary logs smoothly. And then use the results of the log to summarize to a DBPE, which is expected to be used as the basis of the dialogue between raters and the appraisee under various performance appraisal systems. Although to document this diary-log based mostly on the regular input and perseverance of the employee. And yet, to become reliable self-reported evidence, a need should attribute to the collaboration of the employer, both in the management system and the daily operating mechanism. The prerequisites of such collaboration are described as follows.

\subsection{Prerequisites and Definitions of the Proposed Model}

\subsubsection{Prerequisites:}

To enable employees to produce reliable DBPE, there should be some pre-required elements in the enterprise/organization:

(1) A certified ISO 9001 quality management system in site,

(2) The knowledge of ISO 10006 (project management) and equips with its operational mechanism,

(3) The weekly man-hours report system and supervisor's regulated review mechanism,

(4) The annual man-hours statistic/auditing system,

(5) A certified management system mandated by the specific industry, g., Capability Maturity Model Integration (CMMI) Maturity Level 3 or above for software development business,

(6) Prior to the commencement of each appraisal period, documentation of the customary and physical record of the work items (at least the agreed possible work items) agreed between employers and employees.

\subsubsection{Definitions}

Two primary functions of a diary log are to report the work content and the associated achievements. The former is to describe what has been done, when, and how long it took to finish the work. The associated achievements elaborate the outcomes, in terms of both the quality and quantity of the work. Because the work results are recorded separately (either in quality or project management system), the focus of the diary should be on the work content. Moreover, this purposeful record must express the specific aggregate activity and the labor density of each aggregate activity per worker's total man-hours in as much detail as possible, as it will be used for subsequent reference. Therefore, it is necessary to avoid the expression of 
"random activity" as that commonly used in the journal style. The "aggregate activity" here mentioned will be formally called "Activity Item (Al)" hereafter in this paper. The Al is considered as the most fundamental unit of record in this paper, which describes the seemingly fragmented daily activities of workers and relates them to individual work performance. The following definitions are adopted in this paper:

(1) Activity item (Al): a kind of aggregate activity, a special combination of activities conducted by the smallest indivisible unit (i.e., an employee) to produce a specific product or delivery a named service. For example, the work to be executed by the employee specified by the company, or various tasks to be performed by a project team member according to the plan, etc.

(2) On duty: a definite period for which an employee spends his/her mental or laborious efforts for the employer or its agents. Such efforts must have objects, e.g., internal, or external customers, themselves or any potential third parties. This includes working in designated places, or in scattered places due to certain circumstances, or even WFH where possible, subject to the employer's appointment or prior consent.

(3) An organization's outcomes (i.e., includes products, rights, services, etc.) must be less than or equal to the sum of the outcomes of all its members. Here, the so-called "members" include the employer, its agents, and the employees. Outsourcing is included in the organization's product, and it also involves the transfer of property rights through the intervention of the above three. Similarly, from the perspective of the competent authority, the transfer of property rights (including the exercise of laws or forces) due to confiscation must be completed by the intervention or reception of a member or members of this competent body.

(4) Social Exchange Period (SEP): the one, who wishes to use equity theory to maintain a humanitarian employment relationship, should evolve their performance appraisal in a habitual routine to the social exchange concept. In Adams's concept (Adams, 1965) "from the start of the social exchange, till it ends, it should be named as the social exchange period. With mutual consensus, SEP could commence on any day of the fiscal year, or ends at any point in the future. This definition does not just accommodate the fiscal year's routine, and yet to benefit the people who gets a transfer, a promotion, or resigns within the fiscal year; and is even fair to the people who just got in. Therefore, this paper uses SEP to represent a clear meaning of the "appraisal period".

\subsubsection{Diary-Based Documentary Method}

Most employees may ignore the importance of the diary for their daily works. However, in this paper, there must be a continuous diary of the whole event of the employee's daily work without any interruption to use it as the performance appraisal evidence. Such a diary shall include at least three ingredients, namely: time, activity description, and memo. While the time and activity description of the diary will be elaborated more lately, the content of the "memo" may include, but not be limited to, the following: 
(1) Immediate matters assigned by supervisor,

(2) One's own immediate schedule and people with, when, things, ,

(3) Special work matters,

(4) Major achievements or milestones.

In practice, no word in brief reminders or abstracts shall be omitted. Furthermore, anyone can determine the start and end time of the "Time" item in such elements by drawing it on a time table with bars in the form of a Gantt chart. Therefore, the real difficulty of the diary log lies in the narrative method of "activity description". That is: how to record fast enough at the scene, and be regarded as the statistical basis of performance appraisal, is a question. As a result, this paper proposes a method to use Al as the narrative of the work and to produce the required DBPE sequentially in the following four steps:

(1) Determine an Al classification and on-duty shorthand method,

(2) Compile the employee's activity dictionary (AD),

(3) Diary practice and man-hours report/statistics,

(4) Edit the performance evidence.

3.2 Activity Item Classification and On-duty Shorthand Method

\subsubsection{Activity Item Classification}

Based on the survey of the activities of employees in the modern enterprises (those who follow the ISO management model), due to the constraints of the management system and the continuous improvement Plan-Do-Check-Audit (PDCA) cycle, these activities can roughly be classified into the following six categories:

(1) Activity with the product: for example, a standard operating procedure (SOP) or a project plan is used to produce physical objects (hardware/software) or services; the delivery object can be customers or internal units/

(2) Learning or providing educational training: the learning activities within the organization.

(3) Evolving/improvement action: including the PDCA work as required by ISO.

(4) Activity required by the organization: for example, the annual staff sports day due to the increase in horizontal communication within the organization, or participation in social welfare and good-neighborly services to the countryside or beach cleaning, etc. 
(5) Internal operations and preparations of the organization, which can be further divided into the following five basic activities:

(a) One's own preparation,

(b) Communication/coordination/guidance of superiors and subordinates of the chain of command,

(c) Horizontal coordination,

(d) Meetings,

(e) Emergency/maintenance incidents.

(6) Assistance: the employee's voluntary behavior in the workplace which must be an altruistic activity.

3.2.2 Job Breakdown Structure (JBS) and Activity Dictionary Coding Rules

This paper refers to the coding pattern of the Gozinto Chart and Work Breakdown Structure (WBS) in project management to deduce the possible solutions in the following two steps:

(1) Based on grounded theory and practice, the Al classification method is deduced, which is the main axis for compiling the AD sequence.

(2) Use the main axis, the employees can compile an annual activity dictionary. For which, each Al should have a series of sequence numbers to represent an activity description under the specific category.

After three years (1998 2002) of field survey and at least 300 anonymous trials and drills, the abovementioned classification has been revised to nine possible Als, that can help employees to document their daily works easily. In other words, this classification is carried out under the guidance of the grounded theory, and saturated coding has been reached by theoretical sampling. After the above drill, this paper discusses continuous, three cross-year experimental cases within two years (i.e., in the year 2003 2004), and anchors the coding mode for both the Al arrangement (when it is within the scope of $A D)$ and the shorthand method. For these, the mentioned coding modes are as follows:

(1) The second order coding of WBS coding mode is adopted, namely, two numbers separated by one decimal point.

(2) Coding scheme:

General rule: the first code is a JBS classification code of the Al, and the second code is the sequence of the work/activity in the current year.

Special rule: 8.1 8.5; under item 8.0, the basic items in the AD are included. The name and order should not be amended. 
The classification is like WBS and named as the "Job Breakdown Structure (JBS)". The structure of the proposed JBS is shown in Figure 1.

With the above-mentioned structure, the definitions of nine possible Als that an on-duty employee will encounter are defined as follows:

1.0 Standard operation procedure (SOP): the operation under the control of the documental management system can be classified as this Al, and its narrative elements are the documentation name and its series number. Any transfer of property rights of this enterprise/organization with another body can only be processed under this article (Al 1.0)

2.0 Project/Plan: for a project-type enterprise/organization, there must be a temple plan for backup. This type of work must be based on its needs, planning/developing its division of labor to tasks, and the latter must be implemented by plan or SOP or instruction. General corporations also occasionally have ad hoc projects, which can be registered and managed in real-time on employees' AD.

3.0 Training/education: the participation of employees in internal/external training or instruction provided by senior personnel (including the planning period).

4.0 Research and development: conduct research activities that are authorized by the immediate supervisor or approved at the request of the employee within the scope of the job/essential competence. For research and development personnel, it is classified as the first item to calculate man-hours and documentaries.

5.0 Evaluation: the activities required by the immediate supervisor to evaluate within the scope of the job/essential competence. For example, participation in the evaluation of plant operations in procurement cases or hazard assessment activities in environmental management. Similarly, for investigators, it will be classified as the first item to calculate man-hours and documentation.

6.0 Assignment: activities assigned by the organization, such as fire drills, neighborhood activities, etc. In addition, internal audits, corrective actions, and preventive actions required in the ISO management model are included.

7.0 Meetings: all horizontal contact activities required by the enterprise during office hours are included. Meetings on department or project coordination can also be included here. Basically, any activity with a group of more than three people, a place, minutes, and the action plan are included. Otherwise, it is directly listed in the peer contact (8.3). In addition, meetings designated by the organization, such as the annual general meeting, the year-end dinner party, the annual sports meeting, etc., are also included.

8.0 Internal matters: this is a preparatory activity within the organization, which is further subdivided by the first-order reduction to accrue the man-hours status of specific preparation items for the suitability review of annual manpower distribution. This Al is subdivided into the following five basic sections (indispensable, but may be added), with the following names and definitions: 
8.1 Preparation: the daily preparation for entering the workplace, such as: preparing tea, warming the machine, turning on the computer, punching in, collecting the equipment, and filling out forms, etc. All unproductive private activities during office hours are included. In addition, the preparation items listed in the SOP are also included in the man-hours of this item. If there is a need for long working hours (working hours over 4 hours), the SOP number is annotated for later return and search. Filling in the diary log and weekly man-hours statistic/report is also included here.

8.2 Interview with the supervisor: the invitation to interview or interview with supervisors on the chain of command is included.

8.3 Peer contact: the coordination among colleagues outside the chain of command (i.e., horizontal coordination) is included.

8.4 Subordinate guidance: individual guidance or performance interview for subordinates' work.

8.5 Accidental events: production stagnation caused by damage of equipment or appliances or insufficient supply of spare parts, without substitute tasks, can be handled in parallel.

9.0 Assistance: this is an employee's spontaneous altruistic behavior during working hours.

Using the above definitions, a comparison matrix of activities described by the ISO systems and that of common practice is shown in Table 1:

(1) The main auditing items request by ISO 9001,

(2) The ISO 10006 requirements,

(3) Common activity demands in general (a common practice).

According to Table 1 the classification method proposed in this paper can cover all possible activities, which includes ISO management system, the norm for project management, and practical operations. In addition, this paper adds the preparation Als (under item 8.0) to make employees' statements more relevant to the unconsidered basic aspects, and to improve the visibility of all aspects of employee performance.

Therefore, by using JBS, the work item code of each Al in AD is determined and an on-site shorthand method tailored for employees takes shape.

\subsection{DBPE Operation Steps:}

After the establishment of the "JBS shorthand method", the diary log operation steps can be started. The usefulness of performance evidence depends on the prior agreement of work objectives and the officially verified statistical data. Therefore, the production of the evidence described in this paper requires the following three stages of work, which must be completed step by step, namely: 
(1) Compiling employees' AD;

(2) Diary daily and statistical report;

(3) Official verification and release of performance data.

For concise explanation, the following section (3.3.1 3.3.3) will quote the statistical tables of the "case study" in Section 4 to describe the steps of this method. For detailed relevant information, please refer to Section 4.

\subsubsection{Compiling Employees' Activity Dictionary}

The compilation of employee's AD must be completed before the beginning of the fiscal year (per current routine) or SEP. As per the Job Description (JD) of the employee, all the possible work items under AI 1.0 (SOP) category shall be introduced into the first part of the employee's AD in sequence (example in Table 2). Following this, the employee shall fill in the AD the remains of JBS categories (i.e., Al 2.0 8.0), which include their supervisor's expected tasks, learning progress, or even the scheduled coordination activities, and so on. Each of them should be equipped with an annual serial number (as shown in Table 3 ), and then, the AD can submit it to the supervisor for review and approval.

\subsubsection{Operation Steps and Man-Hours Statistic Model of the Diary log}

This section explains the operation of the diary log, including "daily record" and "man-hours report and statistics model", as follows:

(1) Daily record: The employees shall record the actual work into their diary log (see Appendix A for details of the form). Wherein, the upper part of the diary is a timetable. It is the place where the employee can draw a horizontal bar to mark the starting and ending time of each operation (see Figure 2).

While documenting, the first step is to look up the serial number of work (Al number) in AD, and then write the Al number into the leftmost column of the diary. According to the time invested, the starting and ending time for each Al shall be represented by a horizontal bar in the Time table (15 minutes per scale). Before the day is off, the time invested is added up in each Al in the right subtotal of each column, and then all the working hours are added in the right column and sum is written into the space for the "Total". The employee should check the total man-hours of the day, which must be equal to the number of attendance hours of the day. In addition, if there is any assignment or special matters to be recorded, they can be filled in the blank column in the lower part of the diary of the day.

The following explains the filling in the Al codes and drawing horizontal bars on the timetable using the diary log in Figure 2 as an example. The diary shown is a work record of employee Kim Zotovsik on Oct. 8, 2003 (Wednesday), and it describes as follows:

09:30 Kim is on-duty; 
09:30 10:15 Discuss the work flow project issues (2.2);

10:15 11:15 Negotiating/consulting with colleagues (8.3);

11:15 11:30 EIP's file management (1.1);

11:30 12:30 Reading group (4.B);

12:30 13:30 Lunch break;

13:30 14:45 Reading group (4.B);

14:45 15:00 Network amendment's issues (2.1);

15:00 15:15 SOP development on GA-023 (4.F);

15:15 15:45 Report to CIO (8.2);

15:45 16:30 ARIS software reception (5.3);

16:30 17:00 Network amendment's issues (2.1);

17:00 18:00 Continue with ARIS tool reception test (5.3);

18:00 18:30 Discuss issues with CIO (8.2); and,

$18: 30$ Kim is off duty.

So, Kim's total man-hours for the day are 8 hours, and the number should fill into the lower right-most column of the upper part of the log of the day (as shown in Fig. 2).

(2) Filling in the weekly report: Before the end of the week (usually on Fridays), the employee shall fill in the man-hours report and a performance cross-check for the consistency of both subtotal (as shown in Table 4). With the correct data, the weekly report can be submitted to the supervisor for review. The supervisor shall request employees to revise any discrepancy of the data or difference in completed items before submission to the HRD.

\subsubsection{DBPE Official Verified Release Data and Self-preparation Matters}

After collecting the weekly man-hours report from employees, the staff of HRD should check the data again, and compare it to the attendance hours of the employee. Then the staff can input these authentic data to the annual man-hour statistics (of the employee) (as shown in Table 5).

After the staff finishes the entering of the man-hours statistics of the 52nd week (or the end of SEP), the statistical results are issued to the employee and their superiors in the form of Table 6 , so the employee can use it to compile a DBPE, and his/her supervisor can also use it as a basis for review. 
With the receipt of the annual man-hours' statistic (Table 6) released by the HRD; the employee can extract the statements from their diary log as a supplement. The summarize statements may include (but not limited to):

(1) Statistics of product produced or service delivered;

(2) Achievement degree of quality index/annual target;

(3) Completion of learning activities;

(4) Significant improvements at work and its investments.

Hence, combining the officially released man-hour statistics during the SEP and supplementary statements; an employee's DBPE is formed.

\subsection{Case Study}

In order to understand the reliability of the JBS shorthand method, this paper conducted (as per the statement of Appendix C) a series of tryouts from the year 2003 until 2020. Within this period, a total of six complete cases are documented. These cases show that the usage of the JBS method can reach a consistent statistical pattern. Besides, amongst these, the closest case related to isolated working style is the first case of these tryouts. Hence, the case is introduced as follows.

\subsection{Case Study-An Isolated Worker's Diary-based Performance Evidence}

This is a closest-distance field survey case (i.e., the observer is the participant). In the year 2001, an era of booming knowledge economy, the protagonist of this paper was invited into a well-known department store, the E company (with more than 2000 employees) in the T-City, served as the manager of the Knowledge Management Center KMC); for which the center is under Information Technology (IT) department. E company complied with none of the prerequisite conditions stated in section 3.1.1.

In the beginning, the participant did not have the idea of the development strategy of KMC nor the basic task of the center, and not even the field he should get involved. With two years' observation and interaction, his functions can be defined as follows:

1. Maintain the login discipline and richness in the file management block of the enterprise portal;

2. Introduce the concept of the documental management system;

3. Develop a series of course for "Team Building", and provide these courses to colleagues (not limited to the IT department);

4. Evaluate Business Process Re-engineering (BPR) tools assigned by Chief Information Officer (CIO).

Therefore, the participant prepared seven items within the Al 1.0(SOP) category, which was as per ISO 20000 (Information Technology Service Management model (ITSM). Then, the annual development 
projects assigned by $\mathrm{ClO}$ were compiled into AD (as detailed in Table 2). After that, the icebreaker items for building a documental management system (including in Al 4.0, 5.0, and 6.0) were formed (Ref. to Table3) and submitted for approval.

Since Feb. 2003, the participant has continuously filled both the diary log and weekly man-hour statistical report as per section 3.3.2. With almost one year's efforts, the data collected from his weekly report is shown in Table 6.

\subsection{Results Interpretation and Findings}

\subsubsection{Results Interpretation}

(1) After nearly one year's diary fulfilling and weekly man-hours report (per Appendix C), it is shown that the JBS shorthand method can indeed assist the employees in completing their on-duty record. In addition, the efforts to fulfill both the man-hours' statistics and the daily record are finite, for which the time consume can be afforded by everyone.

The case study presented in this paper demonstrates that using the JBS shorthand method can help any worker to take a holistic record at the scene. After that, with the combination of the official released statistics report, the best evidence required by PPAS has been produced. This evidence is indeed needed for both the isolated workers and works from home.

(2) In the absence of prerequisite conditions in Company E, the participants in the case study established a documental management system (Per ISO 9001 Standard) in Enterprise Portal, and established SOPs that comply with the ISTM standard according to the nature of the business. Under the project items (AI 2.0), in accordance with the requirements of ISO 10006, the minimum indivisible characteristics of each task were also mandated; the protagonist of this case not only stirred up his main works/tasks in SEP and its quality/target in one stroke (i.e., have a consistent explanation to all the stakeholders of his work), but also, at the same time, marked the norm for performance review. With these efforts, the MBO approach suggested by previous researchers can be realized.

(3) To demonstrate the strength of DBPAE, the annual statistical results of the case (as shown in Table 6) could be interpreted (exemplary) as follows:

(a) In terms of the overall work of this employee, the total annual man-hours were 1,625 hours, and the Als divided it into nine categories (as in Table 7).

(b) Seven major processes were expected to be handle within this SEP, but four of them were not started due to the delay of the Enterprise Resource Planning (ERP) delivery schedule. The remaining three processes took 63 hours (accounting for $88 \%$ of the total annual man-hours). The time and proportion of each item are mentioned in Table 8: 
The most important of these processes is: Al 1.1 Document Management (KM-WI-001). It is the file login process of the enterprise portal, as well as the expansion of the information richness of the block. This year, this type of file management was expanded to the following three areas of operation:

- Build-up and maintain a Documental Management System (DMS) as per ISO 9001 standard; i.e., four levels of documentation section.

- Management and publishing of SOP files of the KM Centre (pre-ITSM) and the Department of Business (DB);

- Collection and publishing of the floor plan of the stores;

(c) In terms of Al 2.0 (Project/Plan) investment, there were 144.75 hours for five projects in total, accounting for $91 \%$ of the total man-hours (see Table 9 for details).

- Al 2.2 is the workflow adopting project completed in 225 hours;

- Network repair case (Al 2.1) was completed in 275 hours (accounting for $1.34 \%$ of the annual manhours).

- IT Equipment Maintenance Project (2.5) is an additional project during the year. It consumed 76.25 hours $(4.69 \%)$.

(4) From the above three examples, the strength of DBPE can be a basis for various types of performance appraisal systems; even the most quantity-demanded appraisal method, i.e., the Balance Scorecard (BSC), can also be applied.

(5) In the end, as states in this case study, the annual statistics described the time invested in the work Als (Al 1.0 7.0) in very precise detail. Yet, it is difficult to judge efficiency one by one. If one can accommodate these data with the supervisor's weekly review, then, whether the efficiency/results of each Als reach its norm or not, can be cognized. This also illustrates the importance of both the weekly review and the management system as mentioned in the prerequisite condition (Sec. 3.1.1).

\subsubsection{Findings}

(1) This paper has the DBPE composed of an employee's diary (namely nine categories of JBS and manhours input proportion) to understand the investment spectrum (whether macro or micro) of the worker from home or isolated worker. The actual size of the diary log (A4 size double-sided printing, 53×3=159 sheets of paper) and statistical calculation sheet (400KB) are both feasible for any employee, in either economic and storage concern. That makes it easier for the worker to secure his/her performance evidence.

(2) Besides that, this study found that the weekly statistical report and official statistical data are helpful for the reflexibility/self-appraisal activities proposed by former scholars. Taking this case study (it is the first tryout of this study) as an example, due to the exercise of the JBS method, the following introspection issues have occurred: 
(a) into improve the operational practice, to draw horizontal bars on the timetable quickly and accurately, when using $1 \mathrm{grid} /$ hour, it is changed to four grids/hour. This can be checked from the revision of the diary log;

(b) The modification of AD coding rules is more conducive to the on-site operation of the JBS method;

(c) To improve AD under Al 8.0, the Al 8.2 needs to be changed to the chain of command system, to the supervisor of Al 8.2 and the subordinates of Al 8.3 to distinguish the difference in working hours.

After the ratee obtains the official statistical data, he/she can conduct a self-appraisal, in cross-reference with the diary. Here the author also uses the content of the case study to cite several items as examples. For which are described as follows:

(a) In terms of internal preparation (Al 8.0), a total of 425 hours $(25.43 \%$ ) were consumed. The durations consumed/distributions are shown in Table 10:

In cross-reference to the proportion of labor investment mentioned in Table 7, is it reasonable that the proportion of internal preparations is more than that of SOPs and projects? And when the author takes a level down, the sub-items Al 8.1 of 133.25 hours and Al 8.3 of 168.75 hours are both higher than the total time consumed in Al 1.0 and the time invested in each individual activity under Al 2.0 (Ref. to Table 6). Therefore, the ratee should go back to the diary to find the reason and the preparing statement for this intuitive misunderstanding, and even ponder over the occurrence of this misunderstanding.

(b) Other than that, there is also an over investment under Al 9.0 (as shown in Table 11), in comparison to Al 1.0. On carefully checking the diary, the ratee begins to recall that most investments herein mentioned are to assist colleagues in his/her SOPs. Therefore, to be statistically intuitive and be convinced of data collection, separate activities such as "SOP Development" should be established under the R\&D item, i.e., Al 4.0.

(3) The company's performance in the SEP of employees will not be limited to the matters described in AD. If it is possible, the temporary response energy is also expected (e.g., Al 2.5). This mentions the addition of AD's item under the JBS method, which is a common occurrence for this setup for contingency. This addition, it not only makes the company's manpower use more flexible but also enables the appraisal system to be more tailored to on-site needs.

(4) According to the prerequisite conditions of this paper, DBPE not only meets the best evidence claimed by PPAS, but also the general job inspection that employers expect. Furthermore, weekly statistics and supervisor's work reminders/reviews, data reporting by HRD's working hours proofreading, and the official released of DBPE make it a good dialogue platform that is not biased to any side of the review, and at the same time, promotes it to be a verified neutral report.

\subsection{Discussion}


The gradual expansion of Generation Z workers and the current pandemic situation has not decreased. As former scholars expected, WFH will eventually become a norm. This study continues the experiments of Greenberg (1987), using a diary-based performance appraisal report as the best 'voice' when the appraisee confronts the rater. This paper provides a preliminary answer to both the difficulty of on-duty log writing and data neutrality through the proposed JBS shorthand method and DBPE.

As illustrated in the case study, DBPE has the full spectrum of performance information and an ability to display of ratee's resilience in SEP, which is hard to find in today's human resource system. Furthermore, in terms of the employees' self-appraisal/reflexibility that has been called for by Roberts (2003), this paper demonstrates its feasibility and entered the level of substantial quantitative review. However, as PPAS was originally treated with the premise of $\mathrm{MBO}$ and this paper is based on the one-by-one quantification of AD to SEP goals, DBPE is indeed the solution to the current performance appraisal processes for works both isolated and work from home. However, this evidence seems to be biased towards the ratee, but the prerequisite conditions (Sec. 3.1.1) proposed by this study turns it into official released statistical data. When this neutral evidence is submitted for review, it will assuredly be acceptable from the reviewer's perspective.

Nevertheless, the author believes that the JBS tryout, herein mentioned, is only an example completed in a perfect contexture. In terms of actual implementation, at least three issues remain to be explored, namely:

1. Although, the diary has always been a tool for cultivating human introspection, its inherent privacy and the continuous perseverance required for implementation are obstacles to its promotion. If the bold innovation that uses the diary log as the performance evidence were not verified by Greenberg (1987), the author would not have been able to come up with the idea. In this study the JBS method was used to prove that DBPE is indeed practical. The one of the remaining questions is: how to make workers willing to, without anticipatory or prevention in psychological aspect, writes down the log, and present it for review?

2. Greenberg (1987) once talked about the concept of organizational justice, and with experiments to verify who should report their performance in the form of a log, and as a 'voice' of their efforts in the SEP. Experiments have proved that for celebrities, they shall receive by distribution justice; for the rest, they are subject to process the review under the guide of procedural justice. For workers both isolated and work from home, the proposed evidence documenting model is necessary. Therefore, worker from home/ isolated worker must be encouraged to use JBS method to show the achievement of promises and its cost-effectiveness, and demonstrate the discipline and introspection ability of the job, which makes it a topic for DBPE promotion.

3. As Dingel \& Neiman (2020) identified the majority of WFH will be the knowledge worker. The case study mentioned in this paper is an example of the operation style of a knowledgeable worker as well as an isolated worker. Despite being on-site, he/she must be in a single line connection to the supervisor; and the operations they involve may still unable to understand by others. The AD, which is compiled by the JBS, now exhibits SEP work objectives and official statistical data under the management mechanism, which still needs an interpretation by the ratee (taking the case study as 
an example). Therefore, the ratee should attain a DBPE and the introspection requirements. At the same time, the company must comply with the prerequisites (Sec. 3.1.1) that are necessary for their protection. Moreover, the expectation of the knowledge worker to the appraisal system should be: 1) not to listen to just one person for deliberations, 2) the decisions that are less than expected will not be disappointing. This paper believes, while promoting JBS, that both the requirements are next critical issues the company will immediately confront.

4. Finally, the case study was conducted in a company that did not meet the prerequisites. The author could not help asking if a company had their appraisal system per the as following criteria: 1) adopts the JBS method, 2) uses PPAS for performance appraisal, 3) has introduced the best evidence review, 4) post-event feedback, can it really improve the overall productivity? These issues are worth discussing.

\subsection{Conclusions}

With the proposed JBS method, an activity dictionary is used to make a prior agreement between employer and employee. A shorthand method is implemented to facilitate workers, both isolated and work from home, to document their work log on duty. It is shown to be useful in assisting both the isolated workers and the raters in the performance appraisal process. The proposed method is practical, can easily produce standardize DBPE, and applicable to workers both isolated and work from home, as well as workers of other working styles.

\subsection{Limitations}

The JBS and shorthand method proposed in this paper is based on the prerequisites (3.1.1) that the enterprise/organization has an established international management system, so that the employees can use standardized Als (Al 1.0) to reach an immediate consensus with the employers, which is also a restrictive condition of using the JBS model to establish DBPE.

\subsection{References}

Adams, J. S. (1965). Inequity In Social Exchange. In L. Berkowitz (Ed.), Advances in Experimental Social Psychology (Vol. 2, pp. 267-299). Academic Press. https://doi.org/https://doi.org/10.1016/S00652601(08)60108-2

Aguilera, A., Lethiais, V., Rallet, A., \& Proulhac, L. (2016). Home-based telework in France: Characteristics, barriers and perspectives. Transportation Research Part A: Policy and Practice, 92, 1-11.

Bernardin, H. J., \& Beatty, R. W. (1984). Performance appraisal: Assessing human behavior at work. Kent Pub. Co.

Bick, A., Blandin, A., \& Mertens, K. (2020). Work from home after the COVID-19 Outbreak. 
Bukh, P. N., \& Mouritsen, J. (2014). Performance Management. Danish J. of Management and Business, 78(3\&4), 3-10.

Delventhal, M. J., Kwon, E., \& Parkhomenko, A. (2021). How Do Cities Change When We Work from Home? Journal of Urban Economics, 103331.

Dingel, J. I., \& Neiman, B. (2020). How many jobs can be done at home? Journal of Public Economics, $189,104235$.

Dockery, M., \& Bawa, S. (2020). Working from Home in the COVID-19 Lockdown. Bentley: Bankwest Curtin Economics Centre.

Greenberg, J. (1987). Using diaries to promote procedural justice in performance appraisals. Social Justice Research, 1(2).

Henderson, R. I. (1984). Performance appraisal. Reston, Va.: Reston Publishing Company.

Islami, X., Mulolli, E., \& Mustafa, N. (2018). Using Management by Objectives as a performance appraisal tool for employee satisfaction. Future Business Journal, 4(1), 94-108.

https://doi.org/https://doi.org/10.1016/j.fbj.2018.01.001

Kandula, S. R. (2006). Performance management: Strategies, interventions, drivers. PHI Learning Pvt. Ltd.

Murphy, K., \& Cleveland, J. (1995). Improving performance appraisal: Designing, implementing and evaluating goal-oriented performance appraisal systems. Workshop presented at the Inaugural Australian Industrial and Organizational Psychology Conference, Sydney,

Roberts, G. E. (2003). Employee Performance Appraisal System Participation: A Technique That Works. Public Personnel Management, 32(1), 89-98. https://doi.org/10.1177/009102600303200105

Viswesvaran, C., \& Ones, D. S. (2000). Perspectives on Models of Job Performance. International Journal of Selection and Assessment, 8(4), 216-226. https://doi.org/10.1111/1468-2389.00151

\section{Tables}


Table 1. Comparison Matrix of JBS and Management Key Items

\begin{tabular}{|l|c|c|c|}
\hline $\begin{array}{l}\text { JBS Article: } \\
\text { Activity Item }\end{array}$ & ISO 9001 & ISO 10006 & Common Practice \\
\hline 1. SOP & $\square$ & & $\square$ \\
\hline 2. Plan & & $\square$ & $\square$ \\
\hline 3. Training & $\square$ & & $\square$ \\
\hline 4. Research & $\square$ & & $\square$ \\
\hline 5. Evaluation & $\square$ & & $\square$ \\
\hline 6. Dispatch Action & $\square$ & & $\square$ \\
\hline 7. Meeting & $\square$ & & $\square$ \\
\hline 8. Internal & & & $\square$ \\
\hline 8.1 Prepare & & & $\square$ \\
\hline 8.2 Supervisor & & & $\square$ \\
\hline 8.3 Peer Affiliation & & & $\square$ \\
\hline 8.4 Subordinate & & & $\square$ \\
\hline 8.5 Incident & & & $\square$ \\
\hline 9. Assistance & & & $\square$ \\
\hline
\end{tabular}

Table 2. Employee Main Activity Item List (An example of Case Study).

\begin{tabular}{|l|l|c|}
\hline \multicolumn{2}{|c|}{ Employee ID: 45203 } & Name: \\
\hline 1.0 & SOP: File Name (Doc. No.) & For Remark \\
\hline 1.1 & Document Management KM-WI-001 & \\
\hline 1.2 & IT User's Manual Update KM-WI-002 & \\
\hline 1.3 & Training text and tool reg. KM-WI-003 & \\
\hline 1.4 & Data Management KM-WI-004 & \\
\hline 1.5 & File Management KM-WI-005 & \\
\hline 1.6 & Performance Review KM-WI-006 & \\
\hline 1.7 & ERP Program file's Reg. KM-WI-007 & \\
\hline 2.0 & Project / Plan & \\
\hline 2.1 & Network Cable Amendment Issues & \\
\hline 2.2 & Work Flow Project & \\
\hline 2.3 & DBSOP Results and Presentation & \\
\hline 2.4 & TO-BE MODEL; for ERP & \\
\hline
\end{tabular}

Table 3 Employee Activity Dictionary (An example of Case Study).

\begin{tabular}{|c|l|c|}
\hline \multicolumn{2}{|l|}{ Employee ID: 45203 } & $\begin{array}{l}\text { Name: Kim } \\
\text { Zotovsik }\end{array}$ \\
\hline 1.0 & SOP: File Name (Doc. No.) & For Remark \\
\hline 1.1 & Document Management (KM-WI-001) & \\
\hline 1.2 & IT User's Manual Update (KM-WI-002) & \\
\hline 1.3 & Training text and tool reg. (KM-WI-003) & \\
\hline 1.4 & Data Management (KM-WI-004) & \\
\hline 1.5 & File Management (KM-WI-005) & \\
\hline 1.6 & Performance Review (KM-WI-006) & \\
\hline 1.7 & ERP Program file's Reg. (KM-WI-007) & \\
\hline 2.0 & Project / Plan & \\
\hline 2.1 & Network Cable Amendment Issues & \\
\hline 2.2 & Workflow Adopting Project & \\
\hline 2.4 & DBSOP Results Presentation & \\
\hline 3.0 & Training & \\
\hline 3.1 & Performance Appraisal Model; by HRD & \\
\hline 4.0 & Research & \\
\hline $4 . A$ & Knowledge and Action Experience Activity & \\
\hline
\end{tabular}




\begin{tabular}{|c|l|l|} 
4.B & $2^{\text {nd }}$ Party Auditing and review & \\
\hline 4.C & $\begin{array}{l}\text { Knowledge acquisition-taking English learning as an } \\
\text { example }\end{array}$ & \\
\hline $4 . D$ & Start with geometry & \\
\hline $4 . \mathrm{E}$ & Start with humanities/historical stories & \\
\hline $4 . \mathrm{F}$ & Develop of SOP & \\
\hline $4 . \mathrm{G}$ & Activity-Based Costing, a concept review & \\
\hline 5.0 & Evaluation & \\
\hline 5.1 & To-Be Model of IT Department & \\
\hline 5.2 & WORK FLOW & \\
\hline 5.3 & Use ARIS as a managerial tool & \\
\hline 5.4 & Xupper, Modeler, a Data Structure Modeling tool & \\
\hline 6.0 & Dispatch (Lecture) & \\
\hline $6 . \mathrm{A}$ & Management System, In General & \\
\hline $6 . \mathrm{B}$ & ISO 9001(Mr. Chen, 3/3) & \\
\hline 6.C & On the trend of E from the financial trends (Mr. Xin, & \\
\hline $6 \mathrm{D}$ & Seven Deadly Sins of Business (Mr. Shen, 5/5) & \\
\hline $6 . \mathrm{E}$ & Project Management (Doc. Shu, 4/14) & \\
\hline $6 . \mathrm{F}$ & ERP Conference & \\
\hline 7.0 & Meeting & \\
\hline 7.1 & Department Meeting & \\
\hline 8.0 & Internal Item & \\
\hline 8.1 & Prepare, Warm-up & \\
\hline 8.2 & Communication, Vertical & \\
\hline 8.3 & Peer Affiliation & \\
\hline 8.4 & Subordinate & \\
\hline 8.5 & Incident & \\
\hline 8.6 & Performance Appraisal & \\
\hline 9.0 & Assistance & \\
\hline & & \\
\hline
\end{tabular}

Table 4. Weekly Man-Hours Report (An example of Case Study). Employee ID: 45203 Name: Kim Zotovsik

\begin{tabular}{|l|c|c|c|c|c|c|c|}
\hline Date & $10 / 6$ & $10 / 7$ & $10 / 8$ & $10 / 9$ & $10 / 10$ & & \\
\hline AI & MON & TUE & WED & THU & FRI & Sub Tot. & $\%$ \\
\hline 1.1 & & & 0.25 & 0.25 & & 0.5 & $1.53 \%$ \\
\hline 2.1 & 1.5 & 0.75 & 0.75 & 0.5 & & 3.5 & $10.69 \%$ \\
\hline 2.2 & & 0.25 & 0.75 & & & 1 & $3.05 \%$ \\
\hline $4 . \mathrm{D}$ & & 5 & & & & 5 & $15.27 \%$ \\
\hline $4 . \mathrm{E}$ & & & 2.25 & 2 & & 4.25 & $12.98 \%$ \\
\hline $4 . \mathrm{F}$ & & 1.5 & 0.25 & 4 & & 5.75 & $17.56 \%$ \\
\hline $4 . \mathrm{G}$ & 0.25 & & & & & 0.25 & $0.76 \%$ \\
\hline 5.3 & 3 & & 1.75 & & & 4.75 & $14.50 \%$ \\
\hline 7.1 & 2 & & & & & 2 & $6.11 \%$ \\
\hline 8.1 & 0.25 & 0.5 & 1 & 0.25 & & 2 & $6.11 \%$ \\
\hline 8.2 & & & & 1.25 & & 1.25 & $3.82 \%$ \\
\hline 8.3 & 1 & & 1 & 0.5 & & 2.5 & $7.63 \%$ \\
\hline Sub Tot. & 8 & 8 & 8 & 8.75 & 0 & 32.75 & $100.00 \%$ \\
\hline
\end{tabular}

Table 5. Employee Man-Hours Accumulation Table (An example of Case Study). Employee ID: 45203 Name: Kim Zotovsik 


\begin{tabular}{|l|c|c|c|c|c|c|c|c|}
$\mathrm{AI}$ & $10 / 10$ & $10 / 17$ & $10 / 24$ & $10 / 31$ & $11 / 7$ & $11 / 14$ & $11 / 21$ & $11 / 28$ \\
\hline 1.1 & 0.5 & 0 & 0 & 0 & 0 & 0.75 & 0 & 0 \\
\hline 1.4 & 0 & 0 & 0 & 0 & 0 & 0 & 0.5 & 0 \\
\hline 2.1 & 3.5 & 1.75 & 0 & 0 & 0 & 0 & 0 & 0 \\
\hline 2.2 & 1 & 0 & 0 & 0 & 0 & 0 & 0 & 0.25 \\
\hline 2.4 & 0 & 0 & 0.5 & 0 & 0 & 0 & 0 & 0 \\
\hline $4 . \mathrm{B}$ & 0 & 7.5 & 7.5 & 3.5 & 2.75 & 2.5 & 3.75 & 4.75 \\
\hline $4 . \mathrm{C}$ & 0 & 0 & 0 & 0 & 0 & 0 & 4 & 0.25 \\
\hline $4 . \mathrm{D}$ & 5 & 0 & 6.25 & 0 & 0 & 0 & 0 & 7 \\
\hline $4 . \mathrm{E}$ & 4.25 & 5.25 & 2.5 & 4 & 0 & 0 & 0 & 1.25 \\
\hline $4 . \mathrm{F}$ & 5.75 & 9.75 & 9.75 & 16.25 & 16.25 & 12.5 & 5 & 3.5 \\
\hline $4 . \mathrm{G}$ & 0.25 & 0 & 0 & 0.75 & 1.5 & 0 & 0.5 & 2.5 \\
\hline 5.3 & 4.75 & 8 & 4 & 0.5 & 0.75 & 10.5 & 1.5 & 1 \\
\hline 7.1 & 2 & 1.75 & 2.25 & 3.25 & 6.25 & 1.75 & 0 & 0 \\
\hline 8.1 & 2 & 3.25 & 3.25 & 3.5 & 3.5 & 2.25 & 5.5 & 5 \\
\hline 8.2 & 1.25 & 1.75 & 0.5 & 0 & 2.25 & 0.5 & 1 & 1.25 \\
\hline 8.3 & 2.5 & 2 & 3.25 & 9.25 & 6.75 & 8.5 & 7.75 & 8.75 \\
\hline 8.4 & 0 & 0 & 0 & 0 & 0 & 0.25 & 0.25 & 0 \\
\hline 8.6 & 0 & 0 & 0.25 & 0 & 0 & 0 & 0 & 0 \\
\hline 9 & 0 & 0 & 1.25 & 0 & 0.5 & 0.75 & 5.75 & 0.25 \\
\hline Sub Tot & 32.75 & 41 & 41.25 & 41 & 40.5 & 40.25 & 35.5 & 35.75 \\
\hline
\end{tabular}

Table 6. Employee Annual Man-Hours Statistic (An example of Case Study)

\begin{tabular}{|c|c|c|c|}
\hline 1.0 & SOP: File Name (Doc. No.) & 63.00 & $3.88 \%$ \\
\hline 1.1 & Document Management (KM-WI-001) & 60.50 & $3.72 \%$ \\
\hline 1.4 & Data Management (KM-WI-004) & 1.00 & $0.06 \%$ \\
\hline 1.5 & File Management (KM-WI-005) & 1.50 & $0.09 \%$ \\
\hline 2.0 & Project / Plan & 144.75 & $8.91 \%$ \\
\hline 2.1 & Network Cable Amendment Issues & 21.75 & $1.34 \%$ \\
\hline 2.2 & Workflow Adopting Project & 24.25 & $1.49 \%$ \\
\hline 2.3 & DBSOP Results Presentation & 1.00 & $0.06 \%$ \\
\hline 2.4 & TO-BE MODEL; for ERP & 21.50 & $1.32 \%$ \\
\hline 2.5 & IT Equipment Maintenance Project (Boa-Shot-Ton) & 76.25 & $4.69 \%$ \\
\hline 3.0 & Training & 7.00 & $0.43 \%$ \\
\hline 3.1 & Performance Appraisal Model; by HRD & 7.00 & $0.43 \%$ \\
\hline 4.0 & Research & 169.25 & $36.25 \%$ \\
\hline $4 . \mathrm{A}$ & Knowledge and Action Experience Activity & 1.50 & $0.09 \%$ \\
\hline $4 . \mathrm{B}$ & $2^{\text {nd }}$ Party Auditing and review & 39.00 & $2.40 \%$ \\
\hline 4.C & Knowledge acquisition-taking English learning as an example & 14.00 & $0.86 \%$ \\
\hline 4.D & Start with geometry & 31.50 & $1.94 \%$ \\
\hline $4 . \mathrm{E}$ & Start with humanities/historical stories & 40.00 & $2.46 \%$ \\
\hline $4 . \mathrm{F}$ & SOP Development & 419.75 & $25.83 \%$ \\
\hline $4 . \mathrm{G}$ & Activity-Based Costing, The concept & 43.25 & $2.66 \%$ \\
\hline 5.0 & Evaluation & 221.75 & $13.65 \%$ \\
\hline 5.1 & To-Be Model of IT Department & 58.25 & $3.58 \%$ \\
\hline 5.2 & WORK FLOW & 13.00 & $0.80 \%$ \\
\hline 5.3 & Use ARIS as a managerial tool & 117.75 & $7.25 \%$ \\
\hline
\end{tabular}


5.4 Xupper, Data Structure Modeling tool

6.0 Dispatch (Lecture)

32.75

39.00

$2.02 \%$

6.A Management System, In General

\begin{tabular}{l|l|}
1.50 & $0.09 \%$ \\
\hline
\end{tabular}

6.B ISO 9001(Mr. Chen, 3/3)

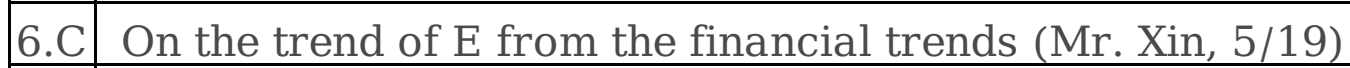

5.75

$0.35 \%$

6.D Seven Deadly Sins of Business (Mr. Shen, 5/5)

8.00

$0.49 \%$

6.E Project Management (Doc. Shu, 4/14)

6.F ERP Conference

7.0 Meeting

7.1 Department Meeting

8.0 Internal

8.1 Prepare, Warm-up

\begin{tabular}{|l|l}
\hline 8.2 & Communication, Vertical \\
\hline
\end{tabular}

\begin{tabular}{l|l} 
8.3 & Peer Affiliation \\
\hline
\end{tabular}

\begin{tabular}{|l|l}
\hline 8.4 & Incident \\
\hline
\end{tabular}

8.5 Performance Appraisal

8.6 Inquire / reception

9.0 Assistance

\begin{tabular}{|c|c|}
6.25 & $0.38 \%$ \\
\hline
\end{tabular}

\begin{tabular}{l|l|}
11.25 & $0.69 \%$ \\
\hline 6.25 & $0.38 \%$ \\
\hline
\end{tabular}

-

(1)

.

\begin{tabular}{|c|c|}
\hline 6.25 & $0.38 \%$ \\
\hline
\end{tabular}

\begin{tabular}{|l|l|}
72.00 & $4.43 \%$ \\
\hline
\end{tabular}

\begin{tabular}{|c|c|}
\hline 72.00 & $4.43 \%$ \\
\hline
\end{tabular}

\begin{tabular}{|l|l|}
413.25 & $25.43 \%$ \\
\hline
\end{tabular}

\begin{tabular}{|c|c|}
\hline 133.25 & $8.20 \%$ \\
\hline 91.00 & $5.60 \%$ \\
\hline 168.75 & $10.38 \%$ \\
\hline 8.25 & $0.51 \%$ \\
\hline 7.25 & $0.45 \%$ \\
\hline 4.75 & $0.29 \%$ \\
\hline 75.25 & $4.63 \%$ \\
\hline
\end{tabular}

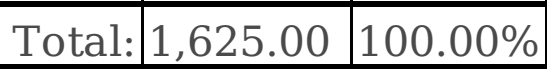

Table 7. Input Time and Respective Proportions of Each AI

\begin{tabular}{|l|l|r|l|}
\hline Activity Item & Work Name & Man-hours & $\%$ \\
\hline 1.0 & SOP & 63.00 & $3.88 \%$ \\
\hline 2.0 & Project / Plan & 144.75 & $8.91 \%$ \\
\hline 3.0 & Training & 7.00 & $0.43 \%$ \\
\hline 4.0 & Research & 169.25 & $36.25 \%$ \\
\hline 5.0 & Evaluation & 221.75 & $13.65 \%$ \\
\hline 6.0 & Dispatch & 39.00 & $2.40 \%$ \\
\hline 7.0 & Meeting & 72.00 & $4.43 \%$ \\
\hline 8.0 & Internal Items & 413.25 & $25.43 \%$ \\
\hline 9.0 & Assistance & 75.25 & $4.63 \%$ \\
\hline & Total: & $1,625.00$ & $100.00 \%$ \\
\hline
\end{tabular}

Table 8. Input Time and Respective Proportions of SOP (AI 1.0) Items

\begin{tabular}{|l|l|r|l|}
\hline Activity Item & Work Name & Man-hours & $\%$ \\
\hline 1.0 & SOP: File Name (Doc. No.) & 63.00 & $3.88 \%$ \\
\hline 1.1 & Document Management (KM-WI-001) & 60.50 & $3.72 \%$ \\
\hline 1.4 & Data Management (KM-WI-004) & 1.00 & $0.06 \%$ \\
\hline 1.5 & File Management (KM-WI-005) & 1.50 & $0.09 \%$ \\
\hline
\end{tabular}

Table 9. Input Time and Respective Proportions of Project (AI 2.0) Items

\begin{tabular}{|l|l|r|r|}
\hline Activity Item & Work Name & \multicolumn{1}{l|}{ Man-hours } & $\%$ \\
\hline 2.0 & Project / Plan & 144.75 & $8.91 \%$ \\
\hline 2.1 & Network Cable Amendment Issues & 21.75 & $1.34 \%$ \\
\hline 2.2 & Workflow Adopting Project & 24.25 & $1.49 \%$ \\
\hline 2.3 & DBSOP Results Presentation & 1.00 & $0.06 \%$ \\
\hline 2.4 & TO-BE MODEL; for ERP & 21.50 & $1.32 \%$ \\
\hline 2.5 & IT Equipment Maintenance Project (Boa-Shot-Ton contractor) & 76.25 & $4.69 \%$ \\
\hline
\end{tabular}

Table 10. Table of Application Distribution of Preparation (AI 8.0) Items \begin{tabular}{|l|l|}
\hline Activity Item & Work Name \\
\hline
\end{tabular} \begin{tabular}{|l|l|l|}
\hline & Man-hours & $\%$ \\
\hline
\end{tabular} 


\begin{tabular}{||l|l|r|l|}
\hline 8.0 & Internal & \multicolumn{1}{|l|}{413.25} & $25.43 \%$ \\
\hline 8.1 & Prepare, Warm-up & 133.25 & $8.20 \%$ \\
\hline 8.2 & Communication, Vertical & 91.00 & $5.60 \%$ \\
\hline 8.3 & Peer Affiliation & 168.75 & $10.38 \%$ \\
\hline 8.4 & Incident & 8.25 & $0.51 \%$ \\
\hline 8.5 & Performance Appraisal & 7.25 & $0.45 \%$ \\
\hline 8.6 & Inquire / reception & 4.75 & $0.29 \%$ \\
\hline
\end{tabular}

Table 11. Man-Hours of Assistance (AI 9.0) and Proportion in Total Man-Hours

\begin{tabular}{|l|l|l|l}
\hline Activity Item & Work Name & Man-hours & $\%$ \\
\hline
\end{tabular}

\begin{tabular}{|l|l|r|r|}
\hline 9.0 & Assistance & 75.25 & $4.63 \%$ \\
\hline
\end{tabular}

Figures

\section{Job Breakdown Structure}

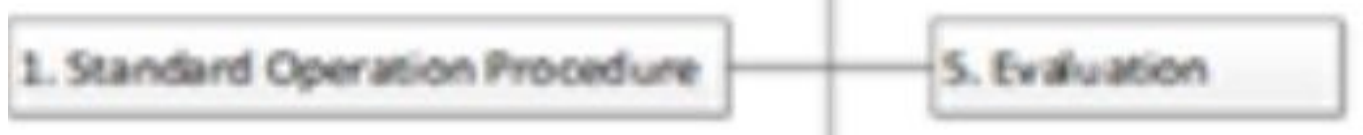

\section{Project / Plan}

\section{Trainine / Teaching}

4. Resieach

\section{Aasisarce}

\section{Neveting}

80 internal

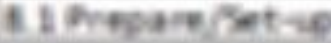

t:16feres

noter ane alish

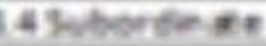

19 incident

\section{Figure 1}


Job Breakdown Structure (JBS)

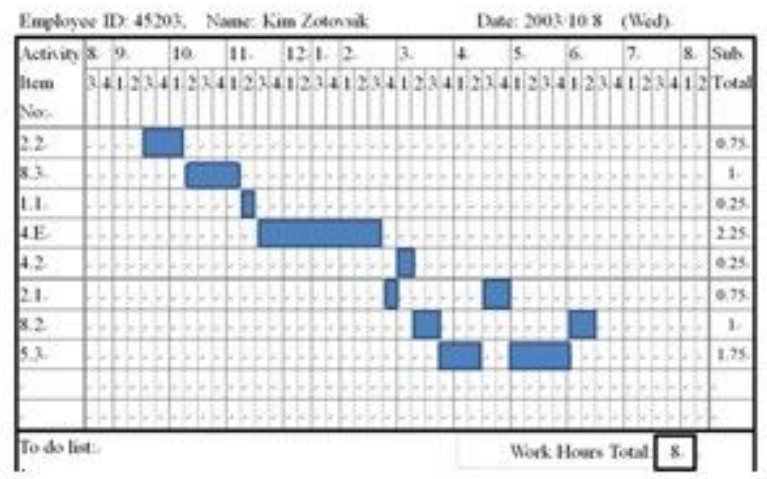

Figure 2

Example for Filling in Als and Time table (Diary log)

\section{Supplementary Files}

This is a list of supplementary files associated with this preprint. Click to download.

- Appendix.docx 